\title{
ARQUITETURA ESCOLAR: UM OLHAR PARA OS LABORATÓRIOS DE CIÊNCIAS
}

\section{SCHOOL ARCHITECTURE: A LOOK AT SCIENCE LABORATORIES}

\author{
DEITOS, Greyze Maria Palaoro ${ }^{1}$ \\ MALACARNE, Vilmar ${ }^{2}$
}

\section{ResUMO}

A arquitetura escolar possui um histórico que não demonstra transformações significativas no que diz respeito às condições físicas e se perpetua ao demonstrar um caráter marcantemente formal e estabelecer rigidez, com pouco dinamismo para a utilização de seus espaços. Em meio a esta questão, este artigo busca responder à pergunta sobre quais as condições arquitetônicas os laboratórios de Ciências, nos anos iniciais das escolas públicas do município de Cascavel, PR, se encontram. A escolha pelo laboratório escolar justifica-se pela relevância das experimentações no Ensino de Ciências. Este estudo percorreu os caminhos da pesquisa bibliográfica, documental e de campo a fim de trazer contribuições significativas a respeito do tema levantado. A partir dos dados da pesquisa, constatou-se que das 51 escolas públicas de Ensino Fundamental I, apenas 8 delas possuem laboratório de Ciências, dentre as quais 5 foram visitadas. A pesquisa indica que a arquitetura escolar precisa se abrir aos programas pedagógicos escolares a fim de proporcionar ambientes condizentes com tais propostas, tornando o espaço escolar um ambiente possibilitador de descobertas e construção do saber.

Palavras-chave: Laboratório de Ciências; Arquitetura Escolar; Ensino de Ciências; Experimentação.

\begin{abstract}
School architecture has a history that does not show significant transformations in terms of physical conditions and is perpetuated by demonstrating a markedly formal character and establishing rigidity, with little dynamism for the use of its spaces. In the midst of this question, this article seeks to answer the question of which are the architectural conditions the science laboratories in elementary public schools in the municipality of Cascavel, State of Paraná. The choice of the school laboratory is justified by the relevance of experimentation in science teaching. This study has followed the paths of bibliographic, documental and field research in order to bring significant contributions on the topic raised. From the research data, it was found that of the 51 public schools of Elementary School I, only 8 of them have a Science laboratory, among which 5 were visited. The research indicates that school architecture needs to be open to school pedagogical programs in order to provide environments consistent with
\end{abstract}

\footnotetext{
${ }^{1}$ Universidade Estadual do Oeste do Paraná (UNIOESTE). Prefeitura Municipal de Cascavel. Cascavel, PR, Brasil. ORCID: https://orcid.org/0000-0002-0524-5176 e-mail: greyzepalaoro@hotmail.com

2 Universidade Estadual do Oeste do Paraná (UNIOESTE). Programa de Pós-Graduação Stricto Senso em Educação em Ciências e Educação Matemática (PPGCEM). ORCID: https://orcid.org/0000-00025222-4722 e-mail: malacarne@unioeste.br
} 
DOI: $10.12957 / \mathrm{e}-\mathrm{mosaicos} .2020 .45711$

such proposals, making the school space an enabling environment for discoveries and construction of knowledge.

KEYWORDS: Science lab; School Architecture; Science Teaching; Experimentation.

\section{INTRODUÇÃO}

Muitas pesquisas trazem contribuições sobre os aspectos que influenciam na melhoria da educação básica em nosso país, como a formação de professores, livros didáticos, metodologias aplicadas, materiais pedagógicos, entre tantos outros elementos que poderiam ser citados. Porém, ao analisar estudos como os de Buffa e Pinto (2002) e Kowaltowski (2011), fica evidente que os autores discorrem sobre a melhoria da educação pelo viés da arquitetura escolar. Eles reúnem aspectos oriundos da arquitetura escolar que interferem diretamente no processo de ensino e de aprendizagem dos alunos.

Imersa nos elementos que favorecem à aprendizagem, a arquitetura escolar possibilita contribuição devido a sua atuação como espaço educativo. Torna-se necessário olhar para o prédio escolar com olhos voltados para a subjetividade que este ambiente representa, pois é muito mais que um espaço físico destinado ao processo escolar, pauta-se em singularidades, atuando diretamente no processo de ensino e de aprendizagem do educando (VIÑAO FRAGO, 2001).

Ainda para Viñao Frago (2001), a arquitetura escolar assume uma linguagem de subjetividade e que, além da materialidade do espaço, reflete-se sobre determinados discursos que, na maioria das vezes, se apresentam veladamente. 0 autor ainda cita que a arquitetura escolar pode ser considerada como elemento do currículo invisível, que se expressa subjetivamente por meio da organização do espaço físico destinado à escola. Ponderando sobre a fala do autor, pode-se questionar os aspectos subjetivos inerentes à presença ou ausência de laboratório de Ciências nas escolas do Ensino Fundamental I, ainda, dentro da existência de tal espaço, que condições este possibilita à produção do conhecimento pelos alunos do Ensino Fundamental?

Como grande parte da população passa considerável tempo de sua vida no espaço escolar, Kowaltowski (2011, p.40) lembra que "[...] é pertinente indagar a respeito do impacto de elementos arquitetônicos sobre os níveis de aprendizagem de alunos e de produtividade dos professores [...]", considerando-os como intermediadores dos processos de ensino e de aprendizagem desenvolvidos na escola, podendo atuar como possibilitadores ou limitadores destes processo. A arquitetura escolar necessita ser pensada entre perspectivas econômicas, sociais, culturais, educacionais e arquitetônicas na intenção de ressignificar seu importante papel na educação, pautada nas potencialidades que o espaço físico pode oferecer em prol da educação como um todo.

É possível projetar espaços de uma maneira diferente da tradicional: espaços que são mais agradáveis e flexíveis, menos rígidos, mais acessíveis para infinitas experiências. $O$ ambiente é visto não como um 
DOI: $10.12957 / \mathrm{e}-\mathrm{mosaicos} .2020 .45711$

espaço monológico estruturado de acordo com um padrão formal de uma ordem funcional, mas como um espaço no qual dimensões múltiplas coexistem, até mesmo as opostas. (CEPPI e ZINI, 2013, p.18)

Ainda na intenção de que se evidenciem elementos facilitadores no processo de aprendizagem dos alunos, elencamos o espaço físico do laboratório escolar de Ciências como espaço singular para o ensino desta disciplina, articulando aspectos distintos em benefício da educação. No intuito de ressaltar tais potencialidades, Rinaldi (2013, p. 123) fomenta que: "[...] é hora de criar esta simbiose entre arquitetura, pedagogia e outras disciplinas a fim de encontrarmos espaços melhores, mais apropriados". O laboratório propicia diversos encaminhamentos metodológicos, que podem ser traduzidos em melhorias no Ensino de Ciências desenvolvido nas escolas do ensino básico, ou seja, desde a educação infantil até o ensino médio.

Em uma pesquisa sobre o uso dos laboratórios de Ciências, Jorge et al (2015, p.127) apontam que "[...] a utilização dos laboratórios no desenvolvimento dos processos educativos vem se intensificando, principalmente por proporcionar a relação teoria e prática, tão cara à compreensão dos conhecimentos em sua totalidade". Convém assinalar a importância das atividades práticas desenvolvidas no laboratório de Ciências, onde a relação entre teoria e prática se torna mais evidente, na busca pela resolução de problemas.

Neste sentido, podemos dizer que o laboratório didático, em seu caráter como um ambiente cognitivo, tão fértil e legítimo quanto qualquer outra situação de ensino, tem um campo de pesquisa promissor ainda pouco explorado do ponto de vista das questões sobre as vicissitudes da experiência de aprendizagem que acontece lá. (BAROLI, LABURU e GURIDI, 2010, p.105)

Partindo-se das premissas evidenciadas quanto à relação existente entre a arquitetura escolar e a educação, direcionamos este estudo, recorte de uma pesquisa de âmbito maior, com a intenção de identificara existência e compreender como se encontra o espaço do laboratório de Ciências na escola, busca-se, nesta pesquisa, responder à seguinte pergunta: Quais as condições arquitetônicas dos laboratórios de Ciências visitados nesta pesquisa? Por fim, apresentamos as considerações provenientes dos estudos teórico e de campo realizados, abordando os aspectos do espaço físico do laboratório de Ciências nas escolas públicas do município de Cascavel.

\section{MetOdOLOGIA}

Esta pesquisa trata de entender o laboratório de Ciências como integrante do ambiente escolar e questionar sua estrutura física e condições de uso. O campo de pesquisa escolhido foi a rede municipal de educação de Cascavel, PR, que conta hoje com 51 escolas de Ensino Fundamental I. Dentre o total de escolas, apenas oito possuem laboratório escolar de Ciências, dentre as oito, cinco delas foram escolhidas para visita e registro fotográfico. A escolha das escolas visitadas seguiu o critério 
estabelecido de permitir que uma escola de cada região (norte, sul, leste, oeste e centro) da cidade fosse contemplada na pesquisa. Com intuito de manter anonimato dos dados apresentados, as escolas foram nomeadas na forma de EM1, EM2...EM5, configurando as iniciais $\mathrm{E}$ de escola e $\mathrm{M}$ de municipal e o número para diferenciá-las entre si.

Três modalidades de investigação foram contempladas para o desenvolvimento desta pesquisa: a pesquisa bibliográfica, a pesquisa documental e a pesquisa de campo. A pesquisa bibliográfica, segundo Marconi e Lakatos (2003, p.183) tem como finalidade: "[...] colocar o pesquisador em contato direto com tudo o que foi escrito, dito ou filmado sobre determinado assunto[...]", desta forma forneceu o embasamento teórico de pesquisadores que já tenham estudado sobre o assunto. Paralelamente à pesquisa bibliográfica, a pesquisa documental também exerceu papel importante na busca por fundamentação em leis ou normas que proporcionassem sustentação ao estudo desenvolvido. Para Marconi e Lakatos (2003, p.174): "A característica da pesquisa documental é que a fonte de coleta de dados está restrita a documentos, escritos ou não, constituindo o que se denomina de fontes primárias", possibilitanto a retomada de tais documentos sempre que necessário.

A pesquisa de campo teve como objetivo compreender in loco as condições arquitetônicas dos laboratórios de Ciências, verificando aspectos arquitetônicos, equipamentos de prevenção a acidentes, material de bancadas e pisos, ventilação, entre outros elementos fundamentais ao bom funcionamento deste ambiente. Foi realizado um registro fotográfico dos laboratórios de Ciências para auxiliar no processo de análise das condições deste espaço.

\section{O PAPEL DA EXPERIMENTAÇÃO E do labORATÓRIO NAS AULAS de CiÊnCIAS}

A educação tradicional foi, durante muito tempo, o modelo de transmissão dos conhecimentos produzidos pela Ciência, em que cabia ao aluno a responsabilidade de ouvir, decorar e reproduzir conceitos e teorias, citando nomes e datas para referendar tal conhecimento. No entanto, essa é uma forma descontextualizada de ensino da Ciência, alicerçada no papel do professor como detentor do saber, delegando ao aluno, a necessidade de reprodução dos conhecimentos, tal qual havia nos livros.

Assim, o ensino de Ciências não articulava os conteúdos acadêmicos com o cotidiano do aluno, e isso contribuía para o desinteresse pela disciplina. Nesta concepção de Ciências como produção individual, Cachapuz et al (2011) apontam que a educação tradicional era a forma usual de ensino e de aprendizagem, sendo assim também o ensino de Ciências, o qual perpassava pela lógica de ouvir, decorar e reproduzir. Da mesma forma, Waldhelm (2007, p.32) nos diz que "[...] o Ensino de Ciências permaneceu bastante formal, ainda baseado no ensino de definições, deduções, equações e em experimentos cujos resultados são previamente conhecidos". Os problemas filosóficos não eram considerados importantes para as questões da Ciência, desta forma, não faziam parte da construção do conhecimento científico, e por assim dizer, do ensino de Ciências. 
DOI: $10.12957 / \mathrm{e}-\mathrm{mosaicos} .2020 .45711$

Para contrariar essa lógica da educação tradicional, onde a reprodução é evidenciada e o aluno exerce papel coadjuvante no processo de aprendizagem, é que na atualidade numerosas pesquisas têm direcionado seus estudos para um processo que inclua a investigação, o questionamento, o levantamento de hipóteses, e tudo isso, utilizando-se da experimentação no ensino de Ciências.

A experimentação se intensificou nas produções científicas para dar credibilidade e veracidade às leis e teorias elaboradas em determinada época, por um único cientista. Esta abordagem epistemológica emerge da empiria, ou seja, do fenômeno, onde "[...] supõe que o conhecimento científico se origina da observação (ou experimentação, ou medição) sistemática da natureza" (ARRUDA e LABURÚ, 2009, p.62). Assim sendo, a experimentação ganha destaque, pois as teorias eram passíveis de comprovação como previa a proposta de Ciência.

No campo das ciências empíricas, desenvolveu-se uma concepção da construção dos conhecimentos científicos fundada no positivismo. A peculiaridade do positivismo caracteriza-se pelas seguintes ideias: o empirismo (o conhecimento parte da realidade de acordo com o modo como os sentidos o percebem, ajustando-se a ela), a objetividade (o objeto de estudo não deve sofrer influência ou intervenção do pesquisador), a experimentação, a validade (mensuração com precisão) e as leis e previsões. Muitas dessas ideias se refletem, até hoje, no ensino, principalmente de Ciências, sob diversas formas de manifestações, permeando consequentemente, o currículo das escolas (MARSULO e SILVA, 2005, p.3).

Muito desta concepção ultrapassou o meio acadêmico e instalou-se nos bancos escolares através de uma educação tradicional. No cotidiano escolar, ainda nos deparamos com um Ensino de Ciências livresco, voltado à transmissão do conhecimento do professor para o aluno. Por outro lado, Barberá e Valdez (1996, p.365) apontam que "[...] sem dúvida, o trabalho prático e em particular a atividade de laboratório constitui um feito diferencial próprio do ensino de ciências". A produção científica possui uma estreita relação com a experimentação, embora o rigor não apresenta a obrigatoriedade, no entanto, vale ressaltar que o Ensino de Ciências se diferencia da Ciência pela abrangência e complexidade das atividades realizadas, contudo tenta mobilizar aspectos para a compreensão desta produção.

Embora os professores sejam unânimes quanto à necessidade da utilização do laboratório para aulas experimentais, segundo Camillo e Mattos (2014), os objetivos divergem bastante e são influenciados diretamente pela concepção de Ciência que os professores possuem. Camillo e Mattos, (2014, p.125) reforçam que "[...] apesar da grande importância atribuída à atividade experimental, está longe de existir um consenso entre professores e pesquisadores acerca da sua utilização, seus objetivos e métodos". Ainda não está claro para a maioria dos professores as diferenças existentes entre as propostas metodológicas que envolvem as práticas experimentais em sala de aula. 
Segundo Espinosa (2010, p.86-87), "[...] o experimento interfere, porém não 'fala' por si só. Quem fala é o pesquisador que observa e vê de maneira coerente ou consistente com o conhecimento de uma época". O autor aponta uma crítica às metodologias tradicionais que utilizam da repetição e reprodução, assinalando que esta proposta não garante o aprendizado do aluno, pois esse realizou etapas préestabelecidas de um processo já identificado. Portanto, não há questionamentos, elaboração de hipóteses, investigação, e assim, não ocorre a produção do conhecimento.

A experimentação deve partir de uma atividade reflexiva perante o que vem sendo observado, pois a repetição não desenvolve estruturas mentais na busca de uma solução. Espinosa $(2010$, p. 89$)$ também discorre sobre a utilização do roteiro e informa que "[...] a situaçaão não estimula uma atitude intelectualmente ativa por parte do aluno, porque pode levá-lo a pensar que sua responsabilidade consiste em seguir essas orientações o mais facilmente possível". Da mesma forma,

O método científico, ao ser questionado, passa a ser denunciado em seu viés de atividade isolada, padronizada; seu caráter instrumentaltecnicista; em seu caráter de exclusão; em sua pretensa neutralidade político-ideológica; em sua importância na elaboração de conceitos; em sua influência na organização das aprendizagens concebidas como ato de repetição e certezas, bem como na influência exercida na construção de programas de ensino prescritivos, técnicos e mecanizados (MARSULO e SILVA, 2005, p.4).

Assim, os questionamentos quanto ao método empirista indutivista começam a se tornar corriqueiros, e novas abordagens quanto à experimentação e ao uso do laboratório de Ciências começam a se estabelecer. Desta forma, uma das questões levantadas frequentemente é referente à participação passiva dos alunos durante os experimentos. $\mathrm{O}$ aluno apenas realiza tarefas já organizadas e chega a um resultado denominado de 'correto' para tal experimento. Para Espinoza (2010, p.84), "[...] não basta propor experimentos: a maneira de apresentar a proposta, as perguntas formuladas e as discussões e reflexões poderão constituir recursos eficazes para o ensino". Assim, tira-se o aluno da passividade e leva-o para ser ativo do próprio experimento, quando se estabelecem relações e reflexões que auxiliarão na construção de um novo conhecimento, ou na reelaboração de um conhecimento prévio.

É a partir dos questionamentos levantados que o conhecimento começa a ser construído, por isso, Barolli, Laburú e Guridi (2010) tratam o laboratório como um lugar privilegiado para o desenvolvimento de atividades em equipe, com investigação, argumentação, problematização, em que é proporcionada a aprendizagem cooperativa adequada. Ainda nesse sentido, Rosito (2011, p.153) enfatiza o elo entre teoria e prática e lembra que "[...] o que foi exposto em sala e o que foi obtido no laboratório precisa se constituir como algo que se complementa. [...], pois as atividades experimentais realizadas sem integração com uma fundamentação teórica não passam de ativismo". A atividade experimental está intrinsecamente ligada às teorias vistas em 
DOI: $10.12957 / \mathrm{e}-\mathrm{mosaicos} .2020 .45711$

sala de aula, pois há indissociabilidade entre elas, ou seja, uma fundamenta a outra para a solução de determinados problemas.

Afim de possibilitar as distintas abordagens metodológicas que se propõem nas atividades experimentais no ensino de Ciências para os Anos Iniciais do Ensino Fundamental, este espaço, denominado de laboratório de Ciências, deve respeitar algumas especificações técnicas, normatizadas pelos órgãos responsáveis pela edificação escolar. A seguir, os elementos específicos da arquitetura escolar serão apresentados como constituintes da educação escolar.

\section{ARQUITETURA ESCOLAR}

Ao se tratar da arquitetura escolar, é necessário referendar por meio de uma análise histórica, que esta esteve e continua envolvida em contextos sócio/políticos/culturais que levam à construção de escolas na urgência de suprir a demanda por vagas no ensino público, sempre crescentes. Muitas circunstâncias impediram a elaboração de projetos que viabilizassem um ambiente mais atrativo e propício para o desenvolvimento infantil. Deliberador (2010) nos fala que a evolução da arquitetura escolar está vinculada com a história da humanidade e consequentemente a importância dada à educação nos períodos históricos que a sociedade percorreu. Poucas foram as experiências que possibilitaram a elaboração interdisciplinar do projeto arquitetônico da escola.

Os projetos escolares envolvem diferentes aspectos que influenciam diretamente no desenvolvimento do projeto arquitetônico escolar, como questões financeiras, culturais, até mesmo desinformação sobre as especificações técnicas referentes ao prédio escolar. Por conseguinte, dentro desta perspectiva, pode-se dizer que toda essa problemática tende a limitar as possibilidades de sucesso na busca por um ambiente escolar de qualidade.

A complexidade do projeto escolar tem como base, em primeiro lugar, o dinamismo da própria educação e seus métodos pedagógicos que demandam constante atualização dos programas arquitetônicos para abrigarem adequadamente as atividades de ensino [...]. A complexidade também se apresenta pelos usuários diversos que a escola abriga: alunos em idades variadas e em etapas de desenvolvimento diferentes, professores, funcionários, pais e membros da comunidade que frequentam a escola. (KOWALTOWSKI, 2011, p.1)

A alternância de concepções e ideais de escola e também a oferta de diferentes métodos pedagógicos afetam diretamente as funções dos ambientes escolares. Vale ressaltar, que as concepções de Ensino de Ciências anteriormente abordadas, influenciam também no espaço escolar considerado como ideal para esta disciplina. Um aspecto arquitetônico relevante a uma proposta pedagógica pode ser irrelevante à outra proposta. 
DOI: $10.12957 / \mathrm{e}-\mathrm{mosaicos} .2020 .45711$

Kowaltowski (2011, p.223) levanta a reflexão sobre ambiente escolar dizendo que: "A discussão deve ter seu foco não apenas no edifício, como também na visão de educação que a comunidade quer na escola". Assim sendo, o espaço destinado às experimentações também depende a compreensão de que modelo de ensino de Ciências a prática está pautada. Nesta direção, confronta-se a necessidade de compreensão da concepção de escola que está sendo projetada e quais os ambientes escolares necessários para que seja potencializado o processo de ensino e de aprendizagem escolar. A concepção de ensino também influencia diretamente a estrutura do prédio escolar, possibilitando a alternância entre rigidez ou flexibilidade do projeto arquitetônico

O laboratório escolar, um entre diversos espaços escolares, propicia aprendizado a partir da ação do sujeito sobre o ambiente, no entanto Barolli, Laburú e Guridi (2010) referendam que embora o laboratório possibilite um ambiente cognitivo fértil e legítimo, ele depende das concepções acerca de Ciência e experimentação que os professores detêm, sendo essas, influências diretas tanto na maneira como se concebe o espaço escolar, como nas práticas pedagógicas desenvolvidas.

\section{NORMATIVAS QUE REgEM A ARQUITETURA ESCOLAR E OS LABORATÓRIOS DE CIÊNCIAS}

Dentro da atual sociedade a arquitetura necessita respeitar diversas normatizações para que, na sua conclusão, as edificações possuam qualidade, estética e eficiência de acordo com os parâmetros estabelecidos por lei. Dentro do município de Cascavel, o Código de Obras é a principal legislação que rege a elaboração de projetos arquitetônicos e estabelece parâmetros mínimos e máximos para elementos construtivos específicos da construção civil. No entanto este documento não estabelece indicadores específicos para os prédios escolares, tampouco para construção de laboratório de Ciências.

Um dos documentos utilizados pelos engenheiros e arquitetos responsáveis pelas obras escolares, da Secretaria de Educação do município de Cascavel, para elaboração de projeto arquitetônico do laboratório de Ciências é a Resolução SESA no 0318, de 31 de julho de 2002, que tem como função: "Artigo $1^{0}$ - Aprovar a Norma Técnica, em anexo, que estabelece exigências sanitárias para instituições de ensinos fundamental, médio e superior bem como cursos livres no Estado do Paraná" (PARANÁ, 2002, p.1). Esta resolução foi estabelecida pela Vigilância Sanitária a fim de tornar os ambientes mais salubres, incluindo o prédio escolar. Nesta Resolução, estão estabelecidas diretrizes específicas do ambiente escolar, com dimensões, materiais e condições sanitárias para garantir habitabilidade a esses ambientes.

Da mesma maneira que o ambiente escolar necessita efetuar o cumprimento de diversas normas específicas, o laboratório de Ciências, enquanto componente desta mesma edificação também deverá obedecer às normas relativas à sua especificidade.

O município de Cascavel, como dito anteriormente, não possui normas próprias para a edificação dos ambientes escolares, tampouco para o laboratório de Ciências. 
DOI: $10.12957 /$ e-mosaicos.2020.45711

Para sanar a ausência de informações, procuramos, em documentos oficiais e publicações sobre o assunto, quais as normativas que deveriam reger a elaboração e construção de um laboratório de Ciências. O primeiro fato observado é que não existe a obrigatoriedade da existência de um laboratório de Ciências para as séries iniciais do Ensino Fundamental. O que há, são especificações individualizadas voltadas para laboratórios de Biologia, Química e/ou Física.

Para os anos finais do Ensino Fundamental, a Secretaria da Educação do Paraná - SEED produziu um caderno com orientação para utilização do laboratório escolar de Ciências da natureza. Neste documento ela afirma que:

Este caderno considera o espaço do laboratório como local onde são ministradas atividades experimentais, podendo ser: o laboratório de Ciências da Natureza, os laboratórios disciplinares (Biologia, Ciências, Física e Química), os laboratórios do curso técnico, dentre eles os laboratórios do Programa Brasil Profissionalizado, criado pelo Governo Federal em 2007, ou outro espaço equivalente para este fim (PARANÁ, 2013, p.10).

Pode-se perceber que essas normativas, embora sejam construídas pelo Estado e não pelo município, fornecem parâmetros que abordam diversas modalidades de laboratório que envolvem as Ciências da Natureza e, portanto, servem de referência para esta pesquisa. Um dos princípios básicos do espaço físico do laboratório escolar de Ciências é proporcionar ambiente adequado e seguro às atividades experimentais nele realizadas, seja pelo professor, seja pelos alunos.

Outro documento pesquisado foi o "Guia de laboratório para o ensino de Química, instalação, montagem e operação", produzido pelo Conselho Regional de Química. Neste guia, normas bem específicas estão presentes para a construção ou reforma de um espaço para ser um laboratório de Química. Ainda o documento cita que "[...] as orientações deste guia tomam como base as Normas Reguladoras (NR's) do Ministério do Trabalho e Emprego (MTE), aprovadas pela portaria no 3.214 de 08 de junho de 1978 e Normas (NR's) da Associação Brasileira de Normas Técnicas (ABNT)" (CRQ, 2012, p.1). Desta forma, as normas reguladoras referentes a este ambiente, estão sendo observadas, por considerar o laboratório de Ciências para os anos iniciais semelhante ao espaço destinado aos anos finais. Na sequência serão enfatizados alguns aspectos necessários para a arquitetura do laboratório escolar de Ciências, observando as normativas estabelecidas pela vigilância sanitária, normativas tidas como parâmetro para a Secretaria de Educação do município de Cascavel.

\section{RESULTADOS}

Esta pesquisa teve como objetivo avaliar as condições arquitetônicas dos laboratórios de Ciências de escolas urbanas do município de Cascavel, PR. Dentre as 51 escolas públicas municipais, somente oito possuem tal ambiente escolar, 
DOI: $10.12957 / \mathrm{e}-\mathrm{mosaicos} .2020 .45711$

totalizando um percentual aproximado de $15 \%$, onde cinco delas participaram até 0 final da pesquisa.

Nos laboratórios visitados, todos os padrões de bancadas são pensados para crianças com estaturas maiores, provavelmente, utilizou-se nesses casos, o padrão estadual, direcionado aos anos finais do Ensino Fundamental. As banquetas são sem encosto, exceto dos laboratórios novos e isso gera desconforto postural na coluna vertebral, conforme pode ser visto na figura 1 . Outro fator importante é a instabilidade desses elementos, que podem levar a queda da criança e causar ferimentos de diversas proporções.

Fig 1: Tipos de banquetas encontradas nos laboratórios visitados

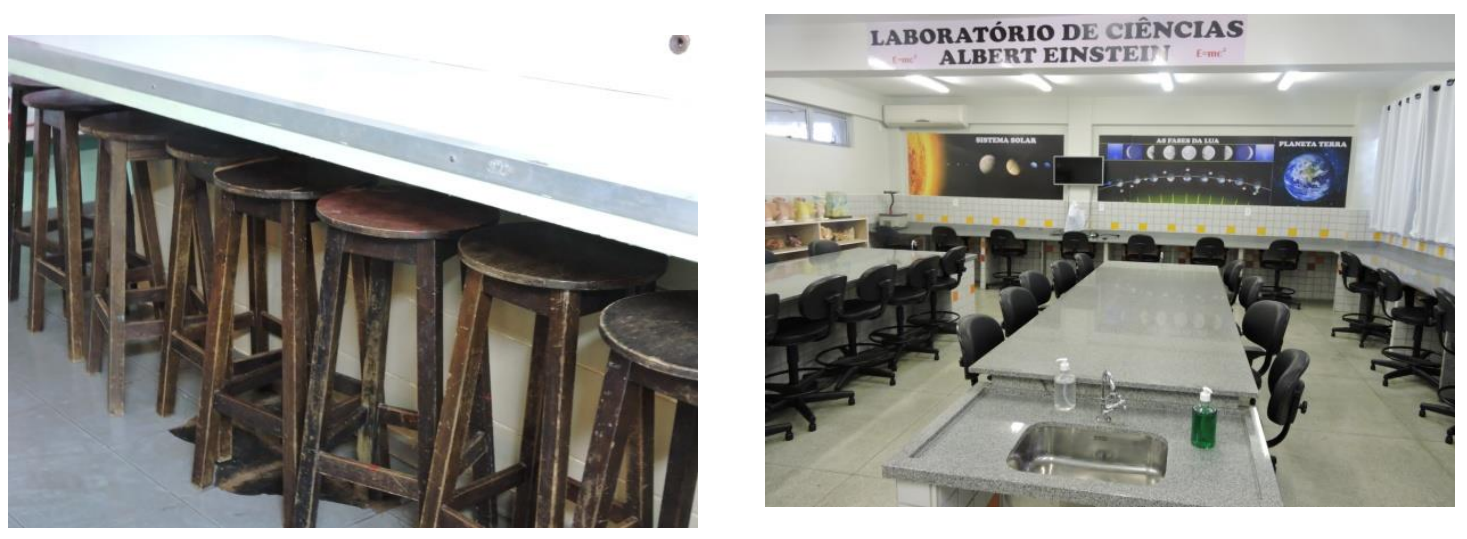

Fonte: dados da pesquisa

No que tange aos aspectos de iluminação natural, artificial e ventilação, todas as escolas estão dentro das normas estabelecidas e possuem ambiente iluminado e ventilado, ou seja, os parâmetros estão em conformidade com o que se espera.

Em relação às portas, existem divergências entre as normas da Vigilância Sanitária, regimentada pela Resolução SESA n¹38/2002 e órgãos de classe como o Conselho Regional de Química - CRQ e a Secretaria de Estado do Paraná - SEED. A Resolução da SESA no 138 prevê a existência de uma porta com dimensões de 80×210 cm com a presença de visor, já para o CRQ e a SEED, existe a necessidade de portas de saída de emergência, constituída de material corta fogo, bem sinalizadas e com abertura para fora, para facilitar a evacuação das crianças dada uma emergência. Dentro desta análise, todas as escolas encontram-se fora das regras, conforme figura 2, qualquer que seja a normatização analisada. 
DOI: $10.12957 /$ e-mosaicos.2020.45711

Fig 2: Modelos de portas encontradas nos laboratórios visitados

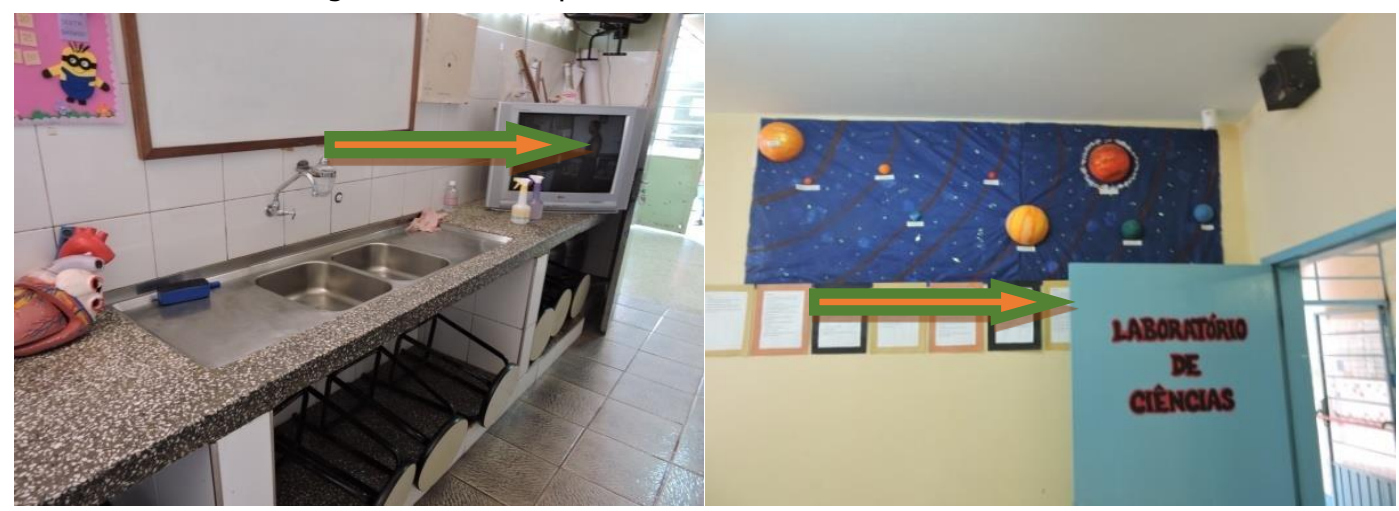

Fonte: dados da pesquisa

Na sequência da análise dos quesitos mínimos, segundo a Resolução SESA n0138/2002, fala-se sobre os revestimentos dos pisos dos laboratórios de Ciências. A resolução informa que o revestimento deve ser íntegro, contínuo, impermeável, lavável, antiderrapante e resistente à limpeza. A escola EM2 utilizou um piso inadequado ao laboratório, com uma resistência menor do que a necessária, aparentando um piso emborrachado que, em contato com a água, desprendeu-se, podendo, assim, causar acidentes.

O piso, segundo CRQ (2012), deve ser regularizado uniformemente de maneira que não apresente saliências ou depressões, nem ocasione acidentes no transporte ou manuseio de materiais. Além deste aspecto, o piso deve ser impermeabilizado, antiderrapante, retardador de fogo, possuir resistência mecânica e física, ser fosco e de fácil manutenção. Na figura 3 são evidenciados três modelos de pisos observados nos laboratórios visitados na pesquisa.

Fig 3: Revestimento do piso dos laboratórios

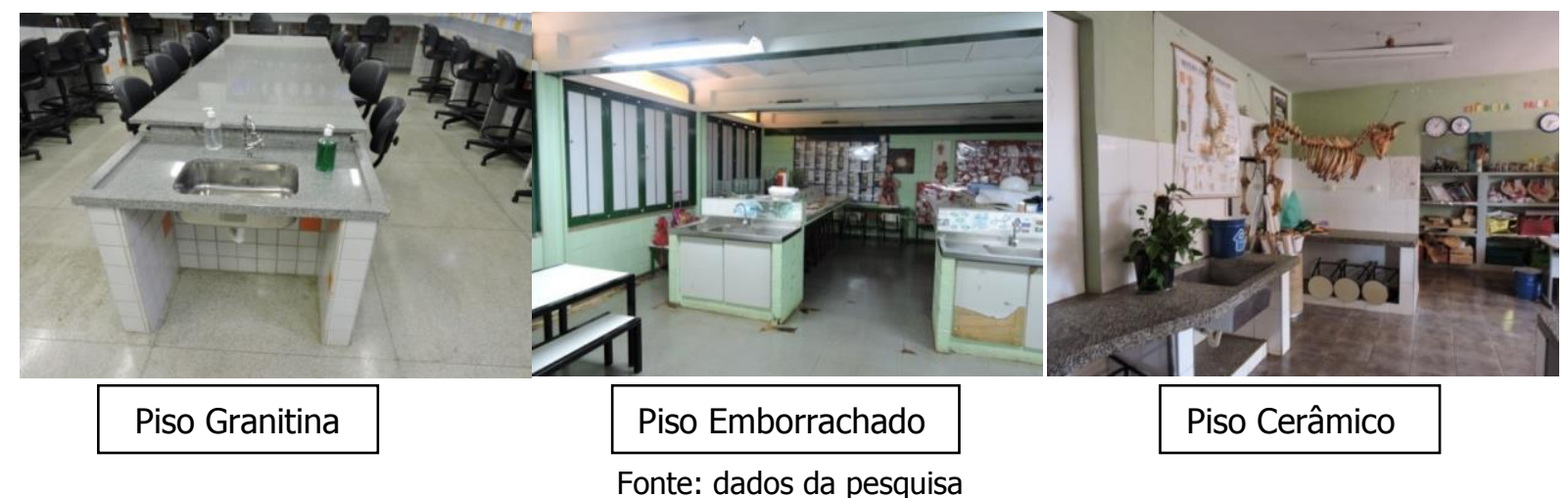

As escolas EM1, EM3, EM4 e EM5 apresentam revestimento de piso adequado ao uso do laboratório de Ciências, sendo utilizado piso cerâmico ou granitina ${ }^{3}$, que

${ }^{3}$ Granitina é um concreto decorativo com um aspecto próximo ao granito natural, de alta durabilidade, fácil manutenção e baixo custo. Asséptico, Alta Resistência, Durabilidade. Fonte: http://www.masterplate.com.br/ 
DOI: $10.12957 / \mathrm{e}-\mathrm{mosaicos} .2020 .45711$

possui características de facilidade de limpeza, durabilidade, e não absorve facilmente produtos líquidos por não ser poroso. Lembrando que o piso do laboratório da escola EM2, por ser emborrachado, pode facilitar a propagação do fogo em caso de acidentes, bem como danificar-se com maior facilidade.

As instalações elétrica, hidráulica e de gás também fazem parte dos prérequisitos para instalação de um laboratório de Ciências. O laboratório da EM5 é o único espaço investigado que não apresenta instalações hidráulicas como torneiras e cubas, contudo a existência da caixa de decantação para resíduos não foi verificada em nenhum dos outros laboratórios visitados, pois os responsáveis não sabiam da sua existência.

As instalações elétricas do laboratório de Ciência, nas escolas com prédio escolar mais antigo, como na EM2 e EM5, necessitam de uma revisão feita por especialista, pois, elas podem estar danificadas ou subdimensionadas para equipamentos que comumente encontramos, como ar-condicionado. O documento utilizado pela SEED (Paraná, 2013, p.13) indica que: "As instalações elétricas e de gás devem estar em boas condições de uso e com manutenção feita periodicamente". Aparentemente a instalação elétrica atende minimamente às necessidades de um laboratório de Ciências, mas sendo necessária uma manutenção constante para evitar riscos de acidentes. Nas escolas, não foram observadas instalações de gás.

Segundo a Resolução citada acima, este ambiente deve estar munido de armários com capacidade para o acondicionamento de reagentes e vidrarias próprias de um laboratório. Os armários devem ser mantidos fechados, preferencialmente chaveados, devido ao perigo que os produtos e vidrarias podem causar às crianças. Todos os laboratórios visitados possuem armários para guardar os materiais específicos conforme vemos na figura 4. No entanto, alguns apresentam problemas nas condições de uso, como: falta de portas, portas que não fecham completamente e a necessidade de troca de alguns devido à deteriorização do material.

Fig 4: Armários dos laboratórios visitados.

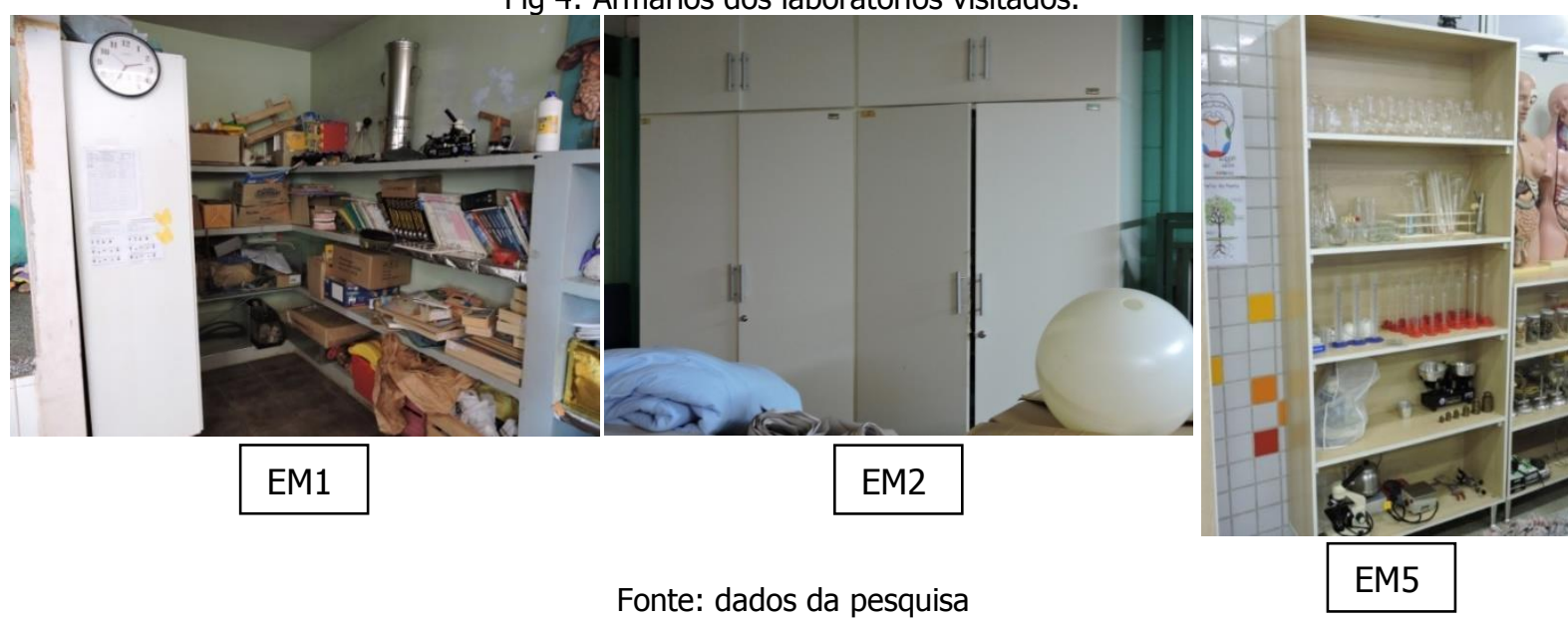


DOI: $10.12957 /$ e-mosaicos.2020.45711

Outro aspecto que deve ser considerado é a falta de manutenção evidenciada pelo desgaste no piso, pintura, banquetas, dentre outros elementos inerentes ao laboratório. A responsabilidade de manutenção dos espaços escolares é da Prefeitura Municipal. Junto à falta de manutenção, se faz necessário enfatizar os problemas relacionados à segurança, como a falta de extintores distribuídos nos laboratórios, cortinas de material inflamável e a presença de chuveiro de emergência em apenas duas escolas, conforme figura 5 . Saídas de emergência não existem, apenas uma porta com abertura para dentro, já apresentada na imagem 2, contrária à recomendação da norma específica, que em caso de necessária evacuação do local, poderia se tornar um elemento limitador e não facilitador.

Fig 5: Chuveiro lava-olhos de emergência
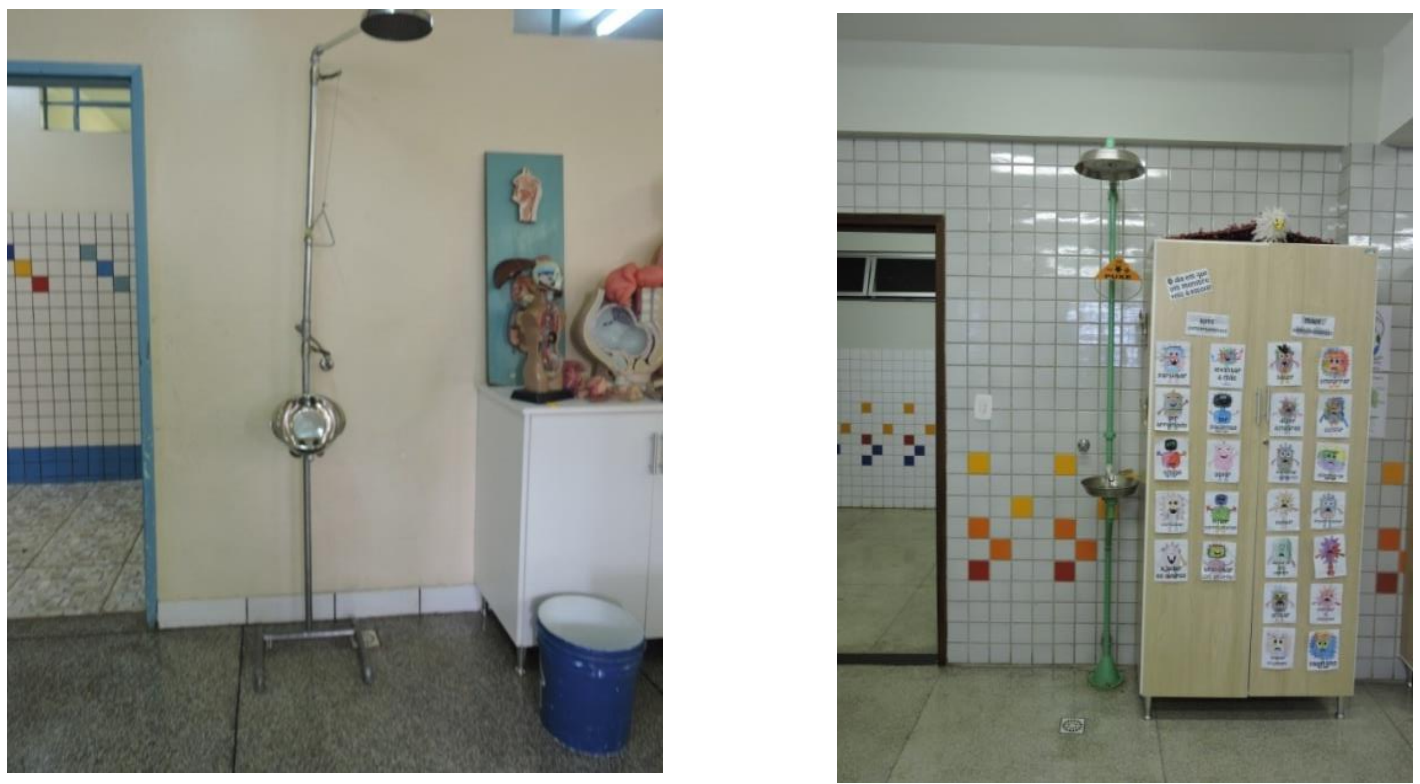

Fonte: dados da pesquisa

Dentre tantas considerações realizadas, percebemos que é urgente um olhar técnico e pedagógico para o ambiente do laboratório, visto que neste espaço muitos são os condicionantes favoráveis à aprendizagem, contudo não devem ser negligenciados aspectos relativos à segurança do ambiente e dos usuários.

\section{CONSIDERAÇÕES FINAIS}

O tema principal abordado nessa pesquisa foi a avaliação da arquitetura dos laboratórios de Ciências das escolas municipais de Cascavel, PR, além de reconhecer os aspectos de segurança e elementos característicos deste ambiente. 0 primeiro ponto a ser levantado referente a este específico espaço escolar foi a sua inexistência, atingindo um percentual de apenas $15 \%$ das escolas contempladas com laboratório de Ciências. 
As condições encontradas nos laboratórios visitados evidenciam certo descaso com o espaço, são muitos reparos nos laboratórios mais antigos, como a troca do piso, pintura, instalação de armários mais seguros, bem como compra de reagentes e vidrarias. Já nos laboratórios das escolas EM3 e EM4, os reparos não são tão necessários, pois fazem parte de uma escola recentemente reformada e outra escola recém construída; sendo essas duas as que mais se aproximam às normativas encontradas nos documentos visitados.

No geral, pode-se evidenciar nas escolas visitadas que a preocupação central, na concepção do laboratório escolar de Ciências, foi direcionada para a construção de bancadas, sistema hidráulico e de ventilação, como requisitos necessários para realização das atividades no local. Por outro lado, aspectos como prevenção de incêndio e saída de emergência são inexistentes na maioria das escolas.

Chama a atenção o caso de laboratórios de Ciências estarem sendo utilizados para outros fins, como sala de artes, na escola EM2, ou acomodações para alunos pertencentes ao programa de escola em tempo integral - ETI, na escola EM5. Isso mostra o descaso com este espaço tão promissor para a aprendizagem, que dirigentes da educação no município demonstram. Aquino (2009) afirma que a escola iniciou suas funções em espaços improvisados, séculos depois, a improvisação se mantém em diversas escolas, como essas visitadas na pesquisa.

Dentre os cinco laboratórios visitados, pode-se dizer que apenas um deles teria condições básicas para atender às crianças nas atividades inerentes ao ensino de Ciências. Aquino (2009, p.73) defende que "[...] reconstruir os significados da escola e seus espaços pode ser uma das medidas que devemos adotar para a mudança do atual modelo educacional". Há que se repensar as condições arquitetônicas do laboratório de ciência, visto que este é um espaço promissor para a aprendizagem dos conteúdos referentes a esta Ciência.

Nota-se que existem normativas específicas para outras etapas da Educação Básica, com especificações bem direcionadas quanto às questões arquitetônicas, no entanto são inexistes para os anos iniciais da Educação Fundamental. Tais especificações auxiliam os profissionais técnicos no processo de elaboração e execução do laboratório de Ciências. A ausência deste material pode levar a erros técnicos, como o caso do piso emborrachado visto na escola anteriormente citada. Desta forma, a elaboração destas normativas se apresenta como uma lacuna a ser preenchida pelos setores competentes por este extrato da educação.

Por fim, faz-se um questionamento relevante ao ensino de Ciências: quando as políticas públicas vão voltar o olhar para as séries iniciais do Ensino Fundamental, além da Alfabetização e da Matemática? Pouco, ou quase nada, foi encontrado nesta pesquisa de normativas que estabelecessem parâmetros para a construção de laboratório de Ciências para esta faixa etária, demonstrando certo desinteresse para essa faixa etária quanto ao ensino de Ciências na perspectiva apresentada neste artigo. 
DOI: $10.12957 / \mathrm{e}-\mathrm{mosaicos} .2020 .45711$

\section{REFERÊNCIAS}

AQUINO, E. C. G. Arquitetura e escola: a percepção docente dos lugares educativos. 2009. 157 f. Dissertação de Mestrado em Educação. Campinas, SP: PUC-Campinas, 2009.

ARRUDA, S. M.; LABURÚ, C. E. Considerações sobre a função do experimento no ensino de ciências. In: NARDI, R. (Org.). Questões atuais no Ensino de Ciências. São Paulo: Escrituras, 2009. p. 59-66.

BARBERÁ, O.; VALDÉS, P. El trabajo práctico en La enseñanza de lãs ciencias: uma revisión. Enseñanza de las Ciencias. v.14, n.3, p.365-379, 1996.

BAROLLI, E.; LABURÚ, C. E.; GURIDI, V. M. Laboratório didáctico de ciencias: caminos de investigación. Revista Electrónica de Enseñanza de las Ciencias. v.9, n.1, p.88-110, 2010. Disponível em:

http://www.docenciauniversitaria.org/volumenes/volumen9/ART6_VOL9_N1.pdf. Acesso em: 19 jan 2017.

BUFFA, E.; PINTO, G. A. Arquitetura e Educação: organização do espaço e propostas pedagógicas dos grupos escolares paulistas, 1893 - 1971. São Carlos: Brasília: EdUFScar, INEP, 2002.

CACHAPUZ et al. A necessária renovação do ensino das ciências. $3^{a}$ ed. São Paulo: Cortez, 2011.

CACHAPUZ, A.; PRAIA, J.; JORGE, M. Da educação em ciência às orientações para o ensino das ciências: um repensar epistemológico. Ciência \& Educação, v. 10, n. 3, p. 363-381, 2004

CAMILLO, J.; MATTOS, C. R. A experimentação no ensino de ciências: reflexões a partir da Teoria da Atividade. In: MAGALHÃES JUNIOR, C. A.; LORENCINI JUNIOR, A.; CORAZZA, M. J. Ensino de ciências: múltiplas perspectivas, diferentes olhares. Curitiba, PR: CRV, 2014.

CEPPI, G. ZINI, M. Crianças, espaços, relações: como projetar ambientes para a educação infantil. Porto Alegre: Penso, 2013.

CRQ - Conselho Regional de Química. Guia de laboratório para ensino de química: instalação, montagem e operação. São Paulo, 2012. Disponível em: http://www.crq4.org.br/sms/files/file/Guia\%20de\%20Laborat\%C3\%B3rio_2012.pdf Acesso em: 25 abr. de 2016. 
DOI: $10.12957 / \mathrm{e}-\mathrm{mosaicos} .2020 .45711$

DELIBERADOR, M. S. O processo de projeto da arquitetura escolar no Estado de São Paulo: caracterização e oportunidades. 2010. 255f. Dissertação de Mestrado em Engenharia Civil. Campinas, SP: Unicamp, 2010.

ESPINOSA, A. M. Ciências na escola: novas perspectivas para a formação dos alunos. Tradução Camila Bogéa. São Paulo: Ática, 2010.

JORGE, C. M. et al. Utilização dos laboratórios padrão MEC nas escolas estaduais do Paraná: o que dizem estudantes e professores. Jornal de Políticas Educacionais, v.9, n. 17, p.125-136, 2015.

KOWALTOWSKI, D. C. C. K. Arquitetura escolar: o projeto do ambiente de ensino. São Paulo: Oficina de Textos, 2011.

LAKATOS, E. M.; MARCONI, M. A. Fundamentos de metodologia científica. 5. ed. São Paulo: Atlas, 2003.

MARSULO, M.A.G.; SILVA, R. M. G. Os métodos científicos como possibilidade de construção de conhecimentos no ensino de ciências. Revista Electrónica de Enseñanza de las Ciencias. v.4, n.3, 2005. Disponível em: http://reec.uvigo.es/volumenes/volumen4/ART3_Vol4_N3.pdf. Acesso em: 10 ago. 2016.

PARANÁ, Secretaria da Educação. Orientações para utilização do laboratório escola de ciências da natureza. Curitiba-PR: SEED, 2013. Disponível em: http://www.biologia.seed.pr.gov.br/arquivos/File/PDF/cadern_lab_2013.pdf. Acesso em: 23 mai. de 2016.

Secretaria da Saúde. Resolução SESA no 0318. Curitiba-PR: SESA, 2002.

Disponível em:

http://www.saude.pr.gov.br/arquivos/File/Legislacao/estudual_resolucao/02RPR318e nsinofundamental.pdf. Acesso em 22 fev. de 2017.

RINALDI, C. O ambiente da infância. In: CEPPI, G.; ZINI, M. (Orgs.). Crianças, espaços, relações: como projetar ambientes para a educação infantil. Porto Alegre: Penso, 2013.

ROSITO, B. A. O ensino de ciências e a experimentação. In: MORAES, R. Construtivismo e ensino de ciências: reflexões epistemológicas e metodológicas. $3^{a}$ ed. Porto Alegre: EDIPUCRS, 2011.

VIÑAO FRAGO, A. Currículo, espaço e subjetividade: a arquitetura como programa. Tradução Alfredo Veiga-Neto. $2^{a}$ ed. Rio de Janeiro: DP\&A, 2001.

WALDHELM, M. C. V. Como aprendeu ciências na educação básica quem hoje produz ciência? O papel dos professores de ciências na trajetória acadêmica e profissional de 
DOI: $10.12957 /$ e-mosaicos.2020.45711

pesquisadores da área de ciências naturais. 2007. 244f. Tese de Doutorado em Educação. Rio de Janeiro, PUC- Rio de Janeiro, 2007.

Recebido em 18 de novembro de 2019

Aceito em 05 de abril de 2020

A e-Mosaicos Revista Multidisciplinar de Ensino, Pesquisa, Extensão e Cultura do Instituto de Aplicação Fernando Rodrigues da Silveira (CAp-UERJ) está disponibilizada sob uma Licença Creative Commons - Atribuição-NãoComercial 4.0 Internacional.

Os direitos autorais de todos os trabalhos publicados na revista pertencem ao(s) seu(s) autor(es) e coautor(es), com o direito de primeira publicação cedido à e-Mosaicos.

Os artigos publicados são de acesso público, de uso gratuito, com atribuição de autoria obrigatória, para aplicações de finalidade educacional e não-comercial, de acordo com o modelo de licenciamento Creative Commons adotado pela revista. 